\title{
Acute Respiratory Failure in a Patient Presenting T-cell Prolymphocytic Leukemia: Specific Leukemic Lung Involvement?
}

Kim Blanc ${ }^{1}$, Aurélie Lefebvre ${ }^{1}$, Nicolas Chapuis ${ }^{2}$, Jerome Tamburini² ${ }^{2}$ Bouscary Didier ${ }^{2}$, Felipe Suarez ${ }^{3}$, Laurent Frenzel ${ }^{3}$ and Antoine Rabbat ${ }^{1}$

${ }^{1}$ Service de pneumologie et Soins Intensifs Respiratoires, Hôpital Cochin, France

2Service d'hématologie, Hôpital Cochin, France

${ }^{3}$ Service d'hématologie, Hôpital Necker, GH Paris centre, AP HP, université René Descartes Paris 5, France

\begin{abstract}
A 36-year old patient with relapsing T-cell prolymphocytic leukemia was admitted in intensive care unit for acute respiratory failure and pulmonary infiltrates. A flexible bronchoscopy with bronchoalveolar lavage was performed while the patient was under noninvasive ventilation. Cytological examination and immunophenotyping of BAL lymphoid cells confirmed the diagnosis of lung infiltration with prolymphocytic T-cell leukemia. An associated organized pneumonia was suspected. The rapid clinical and radiological response to corticosteroids followed by immunotherapy with alemtuzumab strengthened our hypothesis. To our knowledge, this is the first reported case of prolymphocytic T-cell leukemia with a specific pulmonary lung involvement associated with an organized pneumonia.
\end{abstract}

Keywords: T-cell prolymphocytic leukemia; Respiratory failure; Leukemic lung

\section{Case report}

A 36-year-old male patient was admitted in intensive care unit (ICU) for acute respiratory failure. He was diagnosed five months before referral with T-cell prolymphocytic leukemia, with massive splenomegaly and hepatomegaly, characterized by bloodstream and bone marrow involvement by mature T-cells harboring $\mathrm{CD} 3+/ \mathrm{dim}$, $\mathrm{CD} 8+, \mathrm{CD} 4-, \mathrm{CD} 5+$ and $\mathrm{CD} 7+$ phenotype. He was initially treated with the purine analog pentostatin. He relapsed after two courses, four weeks before respiratory symptoms onset. On admission in ICU, respiratory rate was 36 cycles $\mathrm{mn}^{-1}$, body temperature was $38.1^{\circ} \mathrm{C}$, arterial pressure was $116 / 79 \mathrm{mmHg}$, heart rate was $128 \mathrm{mn}^{-1}$. Clinical examination found mild lung crackles, cardiovascular examination remained normal. Transthoracic echocardiography was normal. Chest CT scan showed worsening of bilateral alveolar condensations (Figure 1). $\mathrm{PaO} 2 / \mathrm{FiO} 2$ was $155 \mathrm{mmHg}$ under noninvasive mechanical ventilation (NIV). Flexible bronchoscopy and bronchoalveolar lavage (BAL) were performed while th ' $\times$ 'atient was continuously supported by NIV. BAL fluid count was $1.9 \times 10^{9}$ cells/l including $84 \%$ lymphocytes and $16 \%$ monocytes without signs of intra-alveolar hemorrhage. A large majority of lymphocytes were large irregular cells with a cytological aspect similar to his known T-cell prolymphocytic leukemia ( $94 \%$ of lymphoid cells were $\mathrm{CD} 3+/ \mathrm{dim}, \mathrm{CD} 8+, \mathrm{CD} 4-$ and expressed the pan-T markers $\mathrm{CD} 5+$ and $\mathrm{CD} 7+)$. BAL microbiological cultures remained negative for bacteria, viruses, fungi and mold. Blood test showed: haemoglobin $11.7 \mathrm{~g} / \mathrm{dl} ; 5.62 \mathrm{G} / \mathrm{L}$ leucocytes with $1.97 \mathrm{G} / \mathrm{L}$ neutrophils, $3.54 \mathrm{G} / \mathrm{L}$ lymphocytes the majority of which were atypical, $0.11 \mathrm{G} / \mathrm{L}$ monocytes and $111 \mathrm{G} / \mathrm{L}$ platelets. $\mathrm{LDH}$ was increased at $476 \mathrm{U} / \mathrm{L}$ (135-225).

Large spectrum empiric antimicrobial therapy was given to the patient and withdrawn after 3 days. Both negative (sterile BAL, normal cardiac function) and positive (alveolar lung infiltrates, detection of T-cell prolymhocytic leukemic cells in the BAL) criteria advocated for a T-cell prolymphocytic leukemia involvement associated with organized pneumonia (OP). Systemic corticosteroids therapy was started on day one after ICU admission. On day 3, immunotherapy with alemtuzumab (an anti-CD52 antibody) was started. Clinical status and arterial oxygenation improved rapidly, as attested by successful
NIV weaning at day 5. Meanwhile, lung alveolar infiltrates decreased on the CT scan (Figure 2). Lung infiltrates completely resolved after 3 months of treatment with alemtuzumab and corticosteroids that were progressively withdrawn. After achievement of a complete remission of T-cell prolymphocytic leukemia, geno-identical allogenic stem-cell transplantation is now planned.

\section{Discussion}

Prolymphocytic T-cell leukemia is a rare (less than $2 \%$ of lymphocytic leukemia in adults) hematological malignancy arising from mature T-cell lymphocytes but generally demonstrating a very aggressive outcome [1]. Besides blood and bone marrow involvement, spleen, liver and lymph nodes enlargement are commonly found in this disease $(60 \%, 50 \%$ and $50 \%$ of cases, respectively) and skin infiltration is detected in up to $20 \%$ of patients [2] but pulmonary involvement has not been reported as yet. In our current report, after exclusion of infectious, cardio vascular, toxic and drug etiologies, a specific pulmonary involvement of $\mathrm{T}$ cell leukemia was suspected, and immunophenotyping of BAL lymphoid cells highly favored this hypothesis: we demonstrate leukemic lung involvement by the detection of T-cell prolymphocytic leukemia cells in bronchoalveolar fluids [3]. The absence of intraalveolar hemorrhage ruled out the hypothesis of a blood contamination of the bronchoalveolar fluids arguing in favor of a specific lung involvement by leukemic cells. Here, clinical and radiological picture associated with a complete BAL analysis including immunophenotyping on BAL lymphocyts is a useful diagnosis tool for detecting specific lung involvement, allowing early therapeutic intervention.

*Corresponding author: Rabbat A, Service de pneumologie et Soins Intensifs Respiratoires, Hôpitaux Universitaires Paris Centre, Hôpital Cochin, 27 rue du Faubourg Saint Jacques, 75679 PARIS cedex 14, France, Tel: +33158412087; Fax:+33158412088; Email: antoine.rabbat@cch.aphp.fr

Received April 12, 2016; Accepted June 13, 2016; Published June 16, 2016

Citation: Blanc K, Lefebvre A, Chapuis N, Tamburini J, Bouscary D, et al. (2016) Acute respiratory failure in a patient presenting T-cell prolymphocytic leukemia: specific leukemic lung involvement? J Clin Respir Dis Care 2: 116. doi: 10.4172/ 2472-1247.1000116

Copyright: (c) 2016 Blanc K, et al. This is an open-access article distributed under the terms of the Creative Commons Attribution License, which permits unrestricted use, distribution, and reproduction in any medium, provided the original author and source are credited. 
Citation: Blanc K, Lefebvre A, Chapuis N, Tamburini J, Bouscary D, et al. (2016) Acute respiratory failure in a patient presenting T-cell prolymphocytic leukemia: specific leukemic lung involvement? J Clin Respir Dis Care 2: 116. doi: 10.4172/2472-1247.1000116
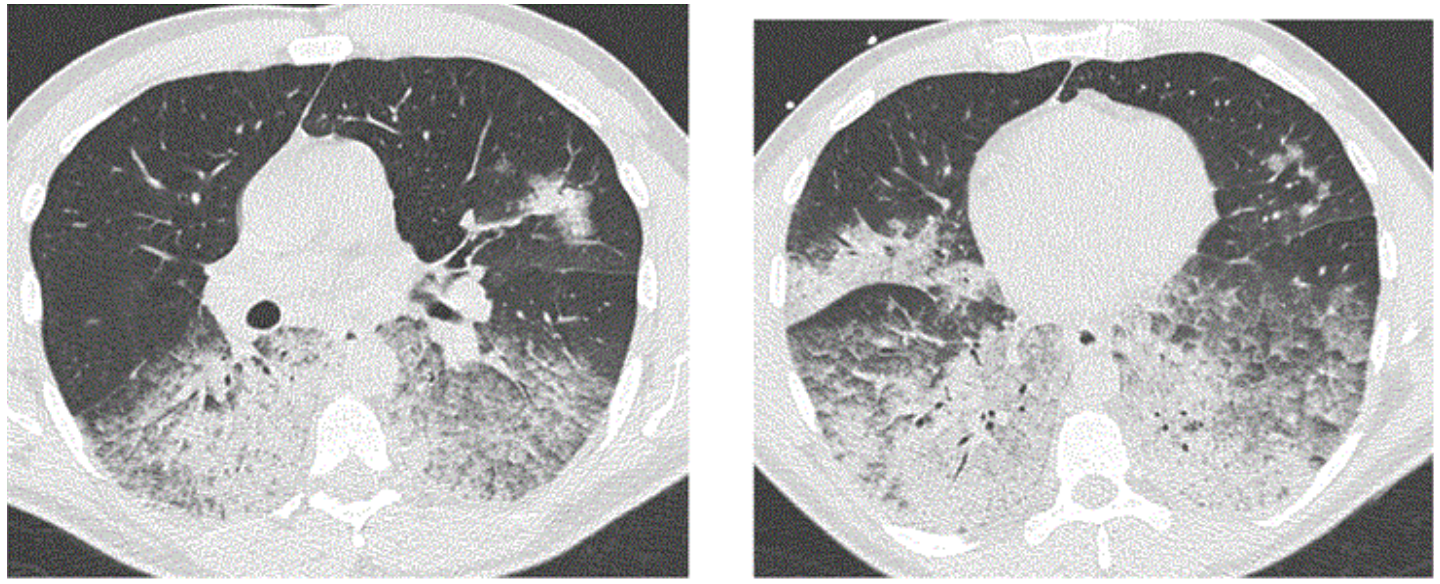

Figure 1: Chest CT scan at admission in intensive respiratory care unit: Diffuses alveolar condensations.
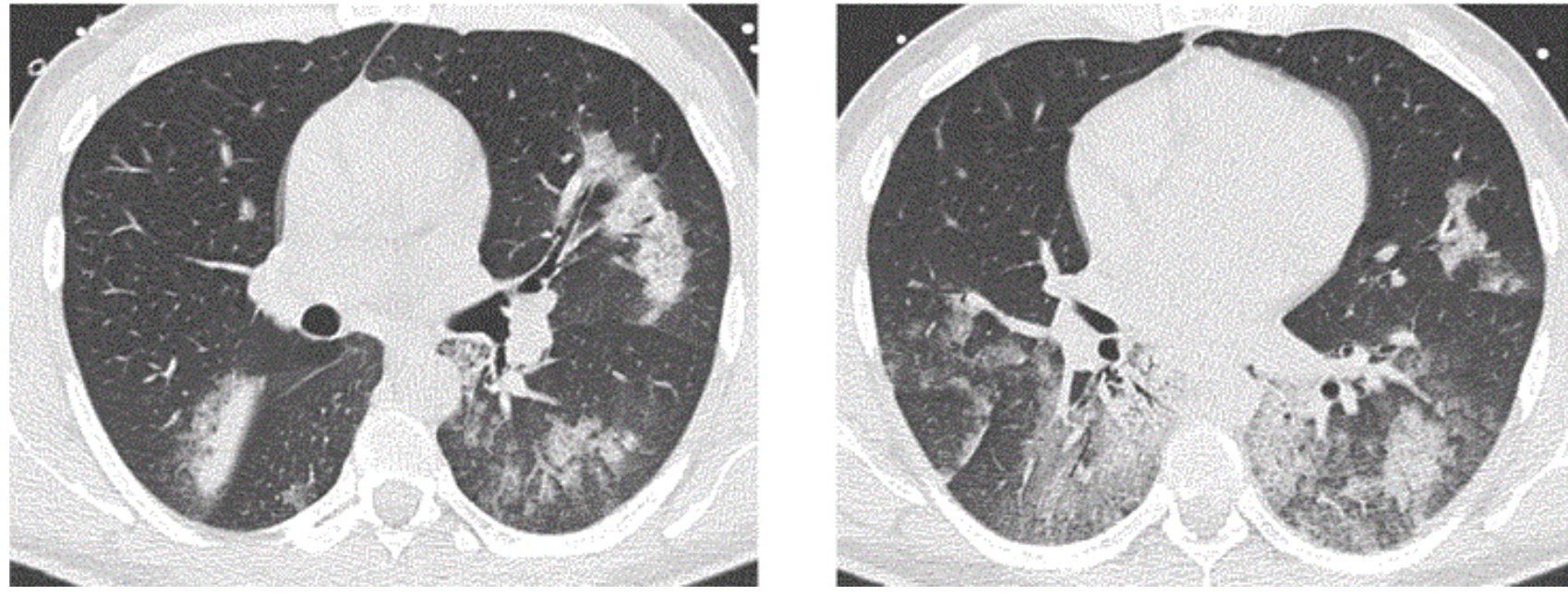

Figure 2: Chest CT scan after 4 days of corticotherapy: Regression of alveolar condensations.

In our current report, we hypothesized that an OP was associated with specific leukemic lung involvement as severe and recurrent episodes of OP have been reported in indolent CD4+/CD8+ T cell leukemia [4]. While definitive proof of this hypothesis could only be given by analysis of lung tissue samples [5], the critical condition of our patient prevented lung biopsy procedures [6].

However, rapid clinical and radiological improvement upon corticosteroid therapy retrospectively strengthened the hypothesis of OP. As noticed previously in OP, alveolar inflammatory lesions are very sensitive to corticosteroid therapy [5]. Indeed, corticosteroid therapy initially given as a monotherapy (i.e. before initiation of alemtuzumab) had no impact on T-cell leukemia tumor burden, supporting the hypothesis that corticosteroids targeted OP inflammatory lesions rather than intra-pulmonary tumor localizations. The diagnosis of $\mathrm{OP}$ is difficult as its clinical and morphological features are shared with those resulting from respiratory infections [5]. Estimated incidence is $34 / 10^{5}$ cases among patients suffering from haematological malignancies [7]. Among this population, OP is mostly diagnosed in a context of infections, radiation therapy, chemotherapy and stemcell transplantation. However, OP is also suggested to arise directly from blood cancers prior treatment initiation and in the absence of documented infection [7]. Co-existence of specific lung involvement was not specified in those reported cases [7].

In our current report, we suggest that phenotypic detection of a clonal haematological disease on BAL fluid is a useful diagnosis tool for detecting specific lung involvement in the etiological investigation of acute respiratory failure, allowing rapid therapeutic intervention.

\section{References}

1. Graham RL, Cooper B, Krause JR (2013) T-cell prolymphocytic leukemia. Proc Bayl Univ Med Cent 26: 19-21.

2. Wiktor-Jedrzejczak W, Dearden C, de Wreede L, van Biezen A, Brinch L, et al (2012) Hematopoietic stem cell transplantation in T-prolymphocytic leukemia a retrospective study from the European Group for Blood and Marrow Transplantation and the Royal Marsden Consortium. Leukemia 26: 972-976.

3. Azoulay E, Mokart D, Lambert J, Lemiale V, Rabbat A, et al. (2010) Diagnostic strategy for hematology and oncology patients with acute respiratory failure: randomized controlled trial. Am J Respir Crit Care Med 182: 1038-1046.

4. Martinez-Gallo M, Puy C, Ruiz-Hernandez R, Rodriguez-Arias JM, Bofill M, et al. (2008) Severe and recurrent episodes of bronchiolitis obliterans organising pneumonia associated with indolent CD4+ CD8+ T-cell leukaemia. Eur Respir J 31: 1368-1372.

5. Cordier JF (2000) Organising pneumonia. Thorax 55: 318-328. 
Citation: Blanc K, Lefebvre A, Chapuis N, Tamburini J, Bouscary D, et al. (2016) Acute respiratory failure in a patient presenting T-cell prolymphocytic leukemia: specific leukemic lung involvement? J Clin Respir Dis Care 2: 116. doi: 10.4172/2472-1247.1000116

6. Lemiale V, Lambert J, Canet E, Mokart D, Pène F, et al. (2014) Identifying cancer subjects with acute respiratory failure at high risk for intubation and mechanical ventilation. Respir Care 59: 1517-1523.
7. Daniels CE, Myers JL, Utz JP, Markovic SN, Ryu JH (2007) Organizing pneumonia in patients with hematologic malignancies: a steroid-responsive lesion. Respir Med 101: 162-168. 